\title{
Human resource allocation for humanitarian organizations: a systemic perspective
}

\author{
Bertha Maya Sopha*, Anna Maria Sri Asih \\ Industrial Engineering Programme, Department of Mechanical and Industrial Engineering, Universitas Gadjah Mada (UGM), \\ Yogyakarta, INDONESIA
}

\begin{abstract}
Human resource allocation appears to be one of the important factors toward effective humanitarian relief operations. Particularly in developing countries, the role of volunteers which is mostly managed by humanitarian organizations has become prominent. Due to the limited human resources, the humanitarian organizations are challenged to allocate their resources to both provide assistance for disaster victims and build organization capacity effectively. The present research aims at identifying effective human resources allocation policy in humanitarian organizations. A formal simulation model was developed using system dynamics approach. Two scenarios, i.e., constant relief demand and empirical relief demand, were developed and tested. Experiments were conducted to examine various allocation policies for both scenarios. Results indicate there is allocation trade-off when it comes to allocate human resources to relief operations and capacity building. Results highlight that allocating resources to capacity building is necessary to sustain relief operations in the long-term.
\end{abstract}

\section{Introduction}

Many literatures such as [1] have indicated that disaster will increase both in number and impact in developed and developing countries. The rise of disasters requires for an increase of need for disaster relief operations. Therefore, the role of humanitarian organizations in providing humanitarian aids such as assessing needs, moving displaced people, caring the wounded, etc., becomes important. Based on empirical evidence, Humanitarian Organizations (HOs) have generally limited resources. But on the other hand, HOs face ever-increasing needs. Consequently, it challenges $\mathrm{HO}$ to improve operational efficiency of both relief operations and capacity building.

HOs have two main activities; one related to capacity building the organizations such as hiring, personnel training, structuring organization, administrative work, and one related to relief operations as their core business activities (assessing needs, designing and implementing transportation of first aid kit, food, equipment, and rescue personnel, transferring and helping disaster victims to the healthcare centres safely and rapidly, moving and helping, providing survival kits, etc.). Allocating the resources to humanitarian relief operations while building sufficient capacity is a challenging task $[2,3]$.

Unfortunately, although HOs have played an important role is disaster relief, only few literatures (e.g., $[3,4])$ have studied the HOs. With respect to human resources, many literature has focused on a more macrolevel such as capacity building of local people [5], and resource coordination among government [6]. Literature on the operation of HOs is however still limited.
Reference [6] has indicated that there is still lack of process documentation, modelling and optimization efforts at humanitarian organizations. Based on the best knowledge of the authors, there are three researches which are specifically addressing the HO operations, i.e., [4] who investigated emergency preparedness strategies such as prepositioning and lead time reduction strategy by HOs, [7] who examined three types of fleet management system, i.e., centralized, decentralized, and hybrid, and [8] who explored the allocation strategies and trade-off between providing relief and building capacity in HOs.

Complementing the previous studies of HOs, the present study aims at exploring the allocation policy for human resources based on local humanitarian organizations in Yogyakarta, Indonesia. It is expected that the study would provide insights for local humanitarian organizations for a better management for volunteers. System dynamics is applied to build formal simulation model that quantifies the effects of various allocation policies.

It is interesting to note that the aforementioned $\mathrm{HO}$ literatures have applied system dynamics as an analytical tool. Following [9], system dynamics is advantageous dealing with dynamic complexity because system dynamics can evaluate both short and long term consequences of the decision, assess the consequences of interactions among variables, and represent dynamic complexity of a system of interest - predicting the effect of changes to the system over time. Further, Reference [7] has demonstrated the appropriateness of system dynamics to be applied in humanitarian operations to examine fleet management system. Briefly, system dynamics is a

\footnotetext{
${ }^{*}$ Corresponding author: bertha_sopha@ugm.ac.id
} 
promising tool as to be used in modeling humanitarian operations which are characterized by multiple feedback loops, uncertainty, and time lags, to understand the consequences of the system change within a long-time horizon.

The rest of the paper is organized as follows. The brief description of system dynamics approach is presented in the next section. The conceptual model using system dynamics approach is presented in Section Three. Section Four describes a simulation model, comprising Stock-and Flow Diagram (SFD), model parameters, model testing, and scenario development in the same section. Section Five presents results and discussion of the scenario development. Finally, the paper is concluded by highlighting the main findings of the study and managerial implications in Section Six.

\section{System Dynamics}

The present study has applied the methodology of system dynamics (please refer to [9] for the details). This section outlines the method to develop system dynamics model which includes model building, model parameterization, and model testing.

The first step is model building. The model is developed using system dynamics approach. System dynamics, typically a top-down approach, is a method using system thinking [10] to enhance learning in a complex system where feedback interactions among system's component occur. It is grounded in the theory of nonlinear dynamics and feedback control developed in mathematics, physics, and engineering [9]. System dynamics is distinguishable from other methods when it comes to the ability to address feedback-loops which determine the dynamic behavior of the system, and to allow changing underlying structure to produce different pattern of behavior. A fundamental principle of system dynamics is based on the assumption that the structure of a system gives rise to its behavior. This is suitable approach when one variable relates with other variables in a complex way. System dynamics is therefore selected for a modeling and simulation tool in this study due to its capability to incorporate causal-links and feedback-loop among influential variables.

Systems dynamics have been widely used for examining several policy intervention models in various contexts such as transportation, population dynamics, product diffusion, inventory, human resources, etc. However, studies related to resource allocation in humanitarian organizations are still very few.

With respect to modeling process, the authors followed [9] who defined the process of system dynamics model consisting of problem articulation, formulating dynamic hypothesis, formulating a simulation model, testing a model, exploring and evaluating policy design. Based on the problem specified in the previous section, a dynamic hypothesis was formulated and a conceptual model was constructed. The conceptual model (presented as Causal-Loop Diagram - CLD) of this present study was built based on observations and interviews with relevant stakeholders of humanitarian organizations. Once the conceptual model has been constructed, the model was validated by respondents of the sampled humanitarian organizations. The respondents of the study are those who have responsibility for human resource management in humanitarian organization. After qualitative validation of the conceptual model, the model was then implemented as a simulation model in the form of Stock-Flow Diagram.

The second step is model parameterization. The simulation model was then parameterized by empirical data which was collected through sets of semi-structured interviews with respondents from the sampled humanitarian organization in 2015 . The questionnaire was specifically designed to provide input parameters for the model. Section 4 specifies the model parameters in detail.

The third step is model testing. To build a model confidence and to assess the degree of representation of the model toward the real system, several steps of model testing from conceptual model to simulation results were conducted through different methods (see Section 4.3 for the details). Scenarios of various human resource allocation policy are then developed and examined with respect to their effectiveness to save affected people.

\section{Conceptual Model}

This section outlines a conceptual model which was presented as causal-loop diagram (CLD) following system dynamics approach [9]. CLD is used as a tool for articulating understanding of the system dynamic and interconnection between parts of the system. The causal loop diagram was drawn empirically through a set of interviews with managers of local HOs in Yogyakarta, Indonesia, in which Mount Merapi, the most active volcanoes in the world - more than 70 eruptions since 1548 [11], resides. The most recent volcano disaster occurred in 2010 which resulted in 400,000 Internally Displaced People (IDP). In addition, earthquake is another disaster that may occur in Yogyakarta. The most recent earthquake occurred in May 27, 2006 which caused 6000 victims. It is therefore HOs in Yogyakarta has played a vital role disaster response.

The HOs generally experience resource limitation particularly human resources because the nature of operation of the HOs in which disasters occur incidentally so that high number of workforces at all time is very costly. As the number of human resources in HOs are generally few, consequently, when disaster occurs, the HOs have to recruit new resources. There are two main tasks of human resources of the HOs, i.e., planning a rescue program, and recruiting new workforce. With respect to recruitment process, the HO staff should conduct interviews toward the workforce candidates in order to assess their capabilities. Both tasks are actually the backbone of the successful rescues. Planning rescue program affects the productivity in the field. Without planning and coordination of the rescue workforces, the rescue process will be ineffective and inefficient. In same way as the planning task, the recruitment of new resources has also impacted on the productivity because incapable human resource may not be able to help the victims. The number of recruited resources is so much depending on 
the number of victims/affected people by disaster. The more victims, the more volunteers/resources to be recruited. Once the victims have been saved, the need for volunteers becomes less and less.

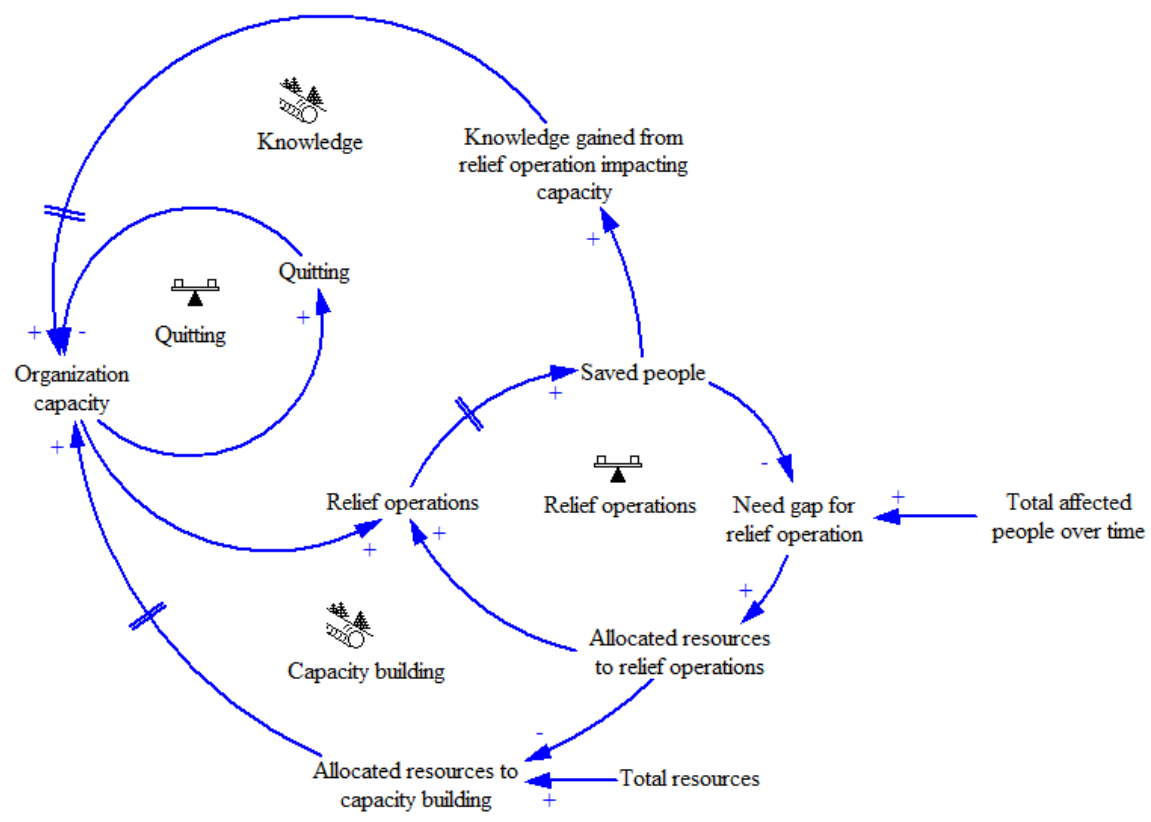

Fig. 1. Causal-Loop Diagram (CLD) of Human Resource Allocation during Disaster Response

Based on the aforementioned facts, the causal-loop diagram articulating the operation of the HOs is presented in Figure 1. The model comprises of two balancing feedback-loops (i.e., relief operation loop and quitting loop) and two reinforcing feedback-loops (i.e., capacity building loop and knowledge loop) detailed as follows.

Relief operations and recruitment are actually two basic operations of the HOs. Relief operation loop, which can be categorize as balancing loop, is triggered by the discrepancy between the total number of affected people and the number of saved people. The more human resources allocated to the rescuing operations leads to higher productivity of operation, which then leads to more affected people being rescued. In same way as relief operations, capacity building loop is depending on the discrepancy between the total number of affected people and the number of saved affected people. The discrepancy influences the human resource to be allocated for recruitment process. As the total available resource is limited, the more allocation to relief operations is corresponding to the lesser allocation for capacity building which then results in less organization capacity. Once the resource for capacity building is allocated, delay occurs to represent training of new resources before the resources can actually contribute to the organizational capacity. The organization capacity then influences the relief operations and consequently less saved people and high gap for the relief operations (Reinforcing loop of capacity building). The organization capacity is also affected by the number of quitting workforce (Balancing loop of quitting). Moreover, the more saved people by the HOs, the more knowledge gained from field which then impact the organization capacity to tackle the relief operations (Reinforcing loop of knowledge).

Based on the empirical conceptual model, it is hypothesized that if HOs allocates more on relief operations than capacity building, the saved people would be higher only in the short-term but fail to sustain in the long-term because the available capacity may not catchup with the increased affected people. On the contrary, if more resources are allocated to capacity building, the number of saved people is lesser in early period but it would later on has more capacity for relief operations.

\section{Simulation Model}

This section are divided into four parts, i.e., description of Stock and Flow Diagram (SFD), parameters of the model, model testing, and scenario development related to human resource allocation policy.

\subsection{Stock and Flow Diagram}

Based on the developed causal-loop diagram of human resource allocation during disaster response (Figure 1), Stock and Flow Diagram (SFD) as a formalized simulation model is developed and shown in Figure 2. Stock and Flow Diagram (SFD) basically consists of sets of simultaneous differential equations. The model was implemented in VensimPLE (by Ventana Systems Inc.).

\subsection{Model Parameters}

The Stock and Flow Diagram model is then parameterized using empirical data. The data for parameterization purpose was acquired from secondary data. However, data which was not available in literatures and specifically characterizes Mount Merapi disaster in Yogyakarta was acquired from semi-structured interviews with the sampled humanitarian organizations. Table 1 describes model parameters and its associated definition and values used in the simulation model 


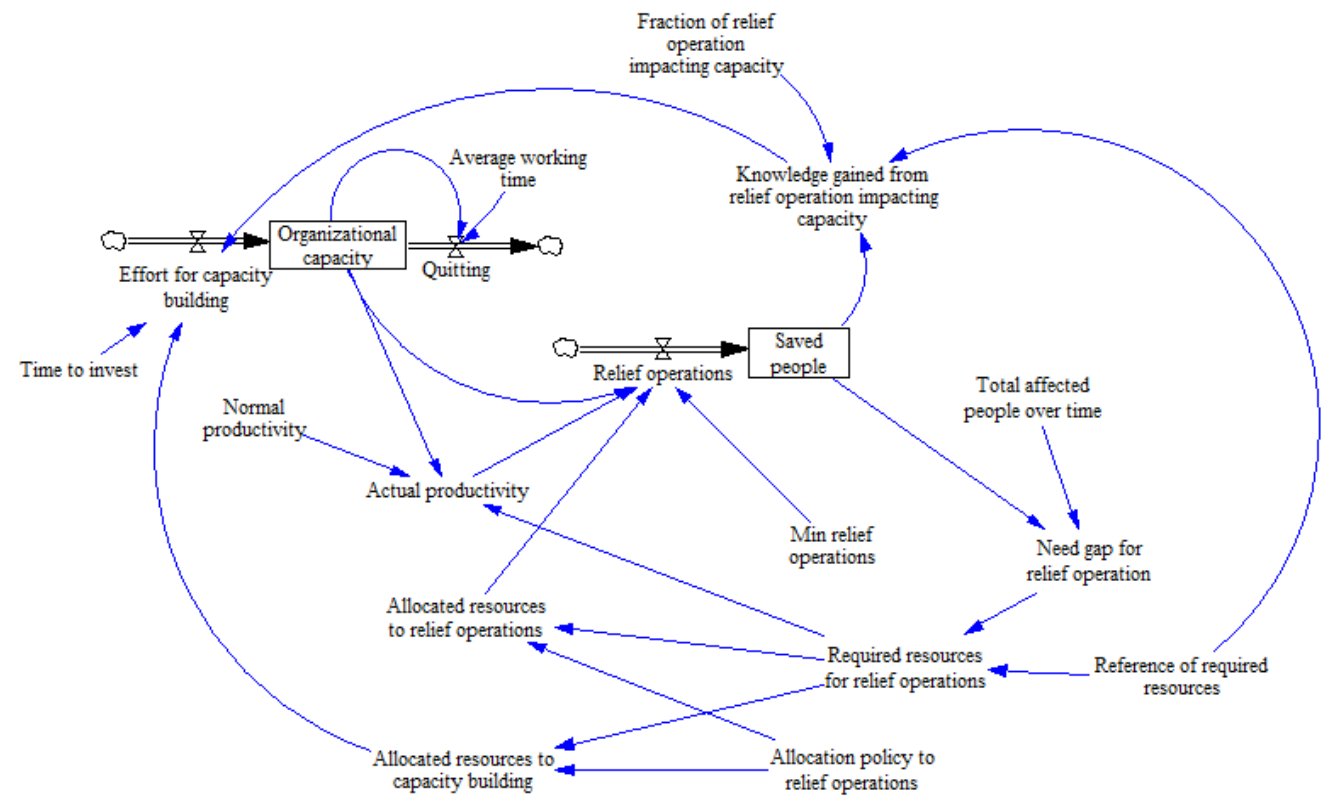

Fig. 2. Stock and Flow Diagram (SFD) of Relief Operations and Capacity Building in Humanitarian Organization

\subsection{Model Testing}

To develop the confidence of the model, a set of tests have been conducted. Three techniques were adopted in this study, i.e., structure verification test, dimensional consistency test, and face validation. Structure verification test examines whether the model is consistent with the knowledge of the real system and relevant to the purpose. This test was conducted through the series of interview with HOs during the process of building the conceptual model. Based on the interviews, the developed causal-loop model has represented actual humanitarian operation during Mount Merapi disaster response.

Dimensional consistency test was conducted using the feature in the VensimPLE which shows that the model is consistent with respect to unit, whereas face validation was conducted by comparing the general patterns produced by the simulation model with the historical pattern with respect to organizational capacity of the sampled HOs. The simulation model has successfully generated the similar pattern of that of the real system (most HOs currently allocates their resources more on relief operations so that the organizational capacity elicited by interviewees is similar to that of pattern Figure 4(b) for relief operations allocation of $80 \%$ of total resources).

\subsection{Scenario Development}

Two scenarios were developed to examine the impact of different pattern of affected people over time. First scenario (base model) uses the constant number of affected people at 1000 people over time. Second scenario uses empirical pattern of affected demand adopted from [12]. For each scenario, various allocation policies to relief operations - fraction of relief operations of $0,0.2$, $0.4,0.6,0.8$, and 1 are simulated to examine the effect of the allocation policy on the dynamics of both organizational capacity and saved people.

Table 1. Model Parameters

\begin{tabular}{|l|l|l|l|l|}
\hline \multicolumn{1}{|c|}{ Parameters } & \multicolumn{1}{|c|}{ Definition } & \multicolumn{1}{c|}{ Value } & \multicolumn{1}{c|}{ Unit } & \multicolumn{1}{c|}{ Sources } \\
\hline Total affected people & $\begin{array}{l}\text { The number of affected people } \\
\text { (victims) over time }\end{array}$ & 1000 & people/day & $\begin{array}{l}\text { Base model: } 1000 \\
\text { people (assumption) } \\
\text { Empirical model: [12] }\end{array}$ \\
\hline $\begin{array}{l}\text { Reference of required } \\
\text { resources }\end{array}$ & $\begin{array}{l}\text { The ratio of standard required } \\
\text { resources and victims }\end{array}$ & 0.00375 & dimensionless & $\begin{array}{l}\text { Government Regulation } \\
\text { No. 7 Year 2008 }\end{array}$ \\
\hline $\begin{array}{l}\text { Minimum relief } \\
\text { operations }\end{array}$ & $\begin{array}{l}\text { Minimum required relief } \\
\text { operation if HO want to operate } \\
\text { in the field }\end{array}$ & 10 & people/day & $\begin{array}{l}\text { Interview with sampled } \\
\text { HOs }\end{array}$ \\
\hline Normal productivity & $\begin{array}{l}\text { The capability of resources to } \\
\text { help victims everyday }\end{array}$ & 5 & $\begin{array}{l}\text { people/(people } \\
\text {.day) }\end{array}$ & $\begin{array}{l}\text { Interview with sampled } \\
\text { HOs }\end{array}$ \\
\hline Time to invest & $\begin{array}{l}\text { The average time to hire and } \\
\text { train new resources }\end{array}$ & 5 & days & $\begin{array}{l}\text { Interview with sampled } \\
\text { HOs }\end{array}$ \\
\hline
\end{tabular}


Table 2. Model Parameters (continued)

\begin{tabular}{|l|l|l|l|l|}
\hline \multicolumn{1}{|c|}{ Parameters } & \multicolumn{1}{c|}{ Definition } & \multicolumn{1}{c|}{ Value } & \multicolumn{1}{c|}{ Unit } & \multicolumn{1}{c|}{ Sources } \\
\hline Average working time & The average time to work in HOs & 30 & days & $\begin{array}{l}\text { Interview with } \\
\text { sampled HOs }\end{array}$ \\
\hline $\begin{array}{l}\text { Fraction of relief operation } \\
\text { impacting capacity }\end{array}$ & $\begin{array}{l}\text { Fraction of relief operation } \\
\text { impacting capacity due to } \\
\text { knowledge gained from the field }\end{array}$ & 0.01 & Dimension-less & $\begin{array}{l}\text { Interview with } \\
\text { sampled HOs }\end{array}$ \\
\hline
\end{tabular}

\section{Results and Discussion}

This section presents results of the two developed scenarios, i.e., base model (assuming the constant affected people of 1000 over time) and empirical model (based on historical pattern of the affected people).

Each scenario is simulated for various resource allocation policies for relief operation $(0-$ no resource allocated for relief operations, $0.2,0.4,0.6,0.8$, and $1-$ all resource allocated for relief operations). Given the pattern of affected people (a), each scenario is examined its performances with respect to organizational capacity (b), saved people (c), and need gap (d). Figure 3 (a, b, c, d) and Figure 4 (a, b, c, d) present results of base model and empirical model respectively.

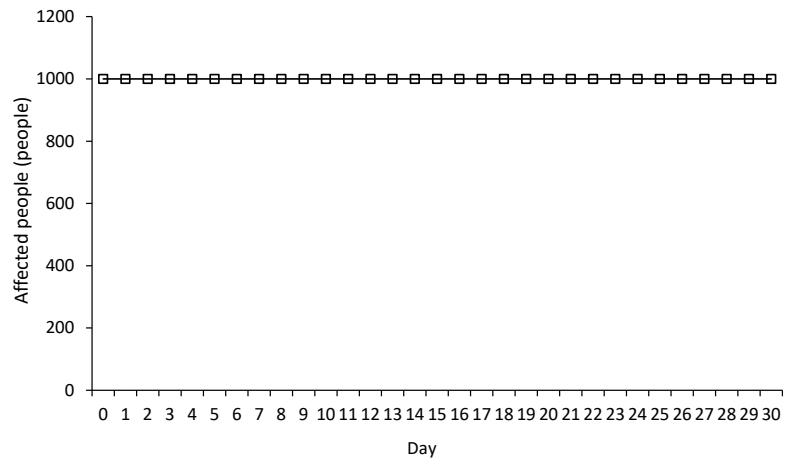

(a). Base Model - Affected People

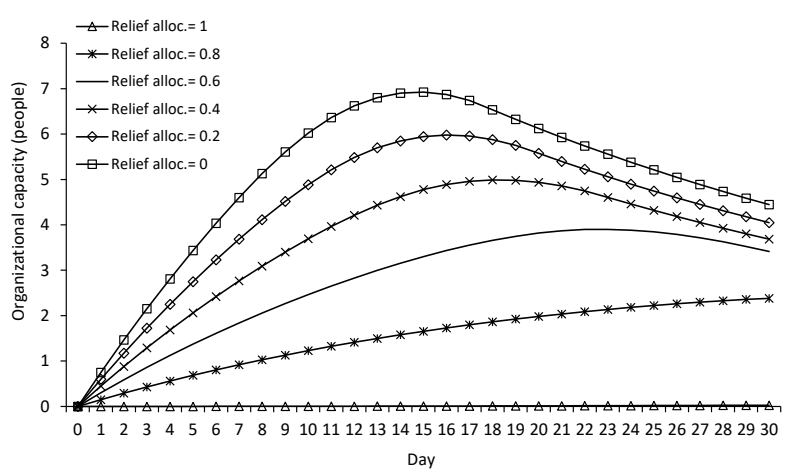

(b). Base Model - Organizational Capacity

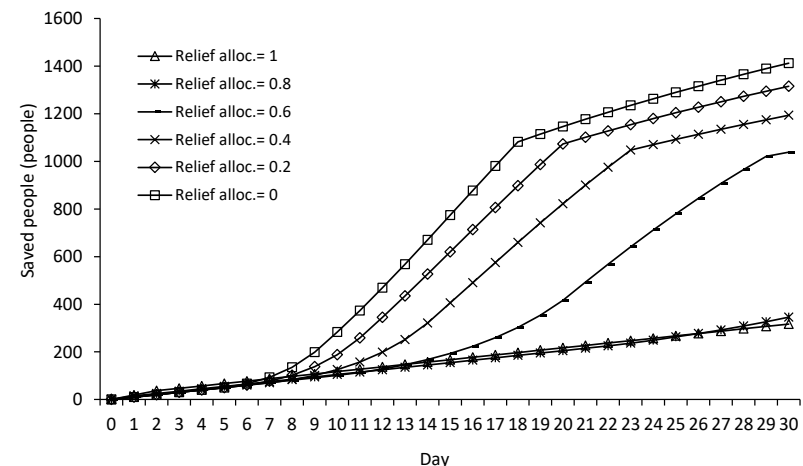

(c). Base Model - Saved People

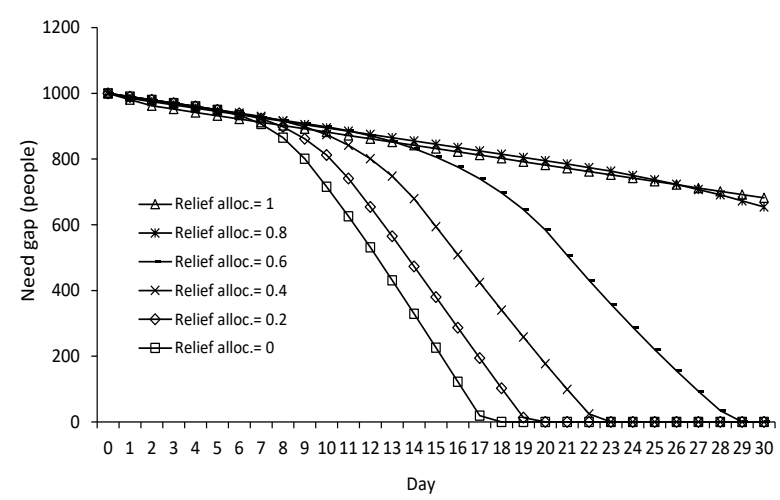

(d). Base Model - Need Gap

Fig. 3. Simulation Results for Base Model (Constant Relief Demand) for Various Human Resource Allocation Policies (ad)

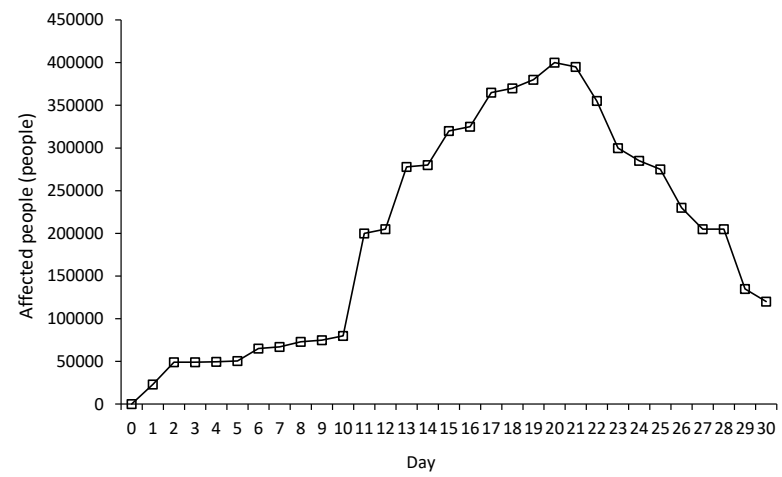

(a). Empirical Model - Affected people 


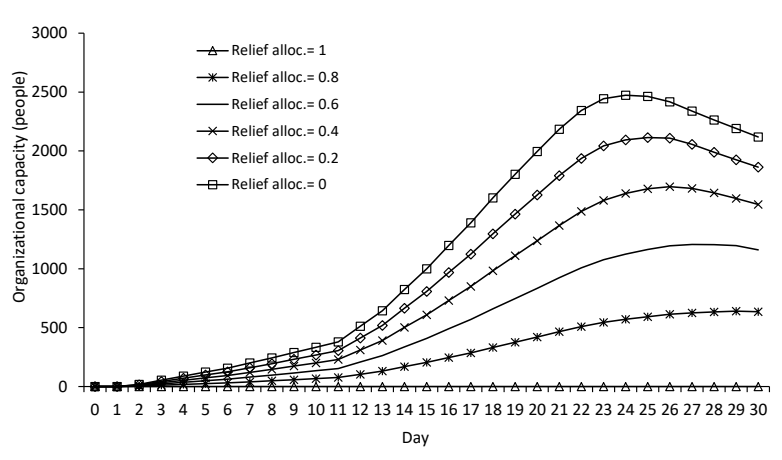

(b). Empirical Model - Organizational Capacity

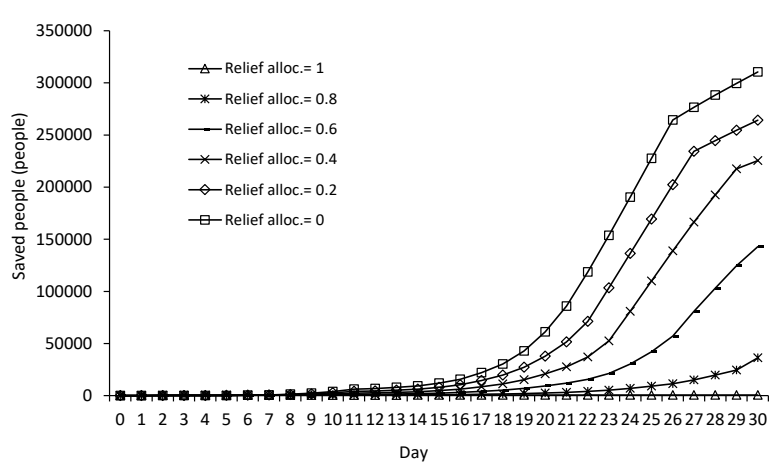

(c). Empirical Model - Saved People

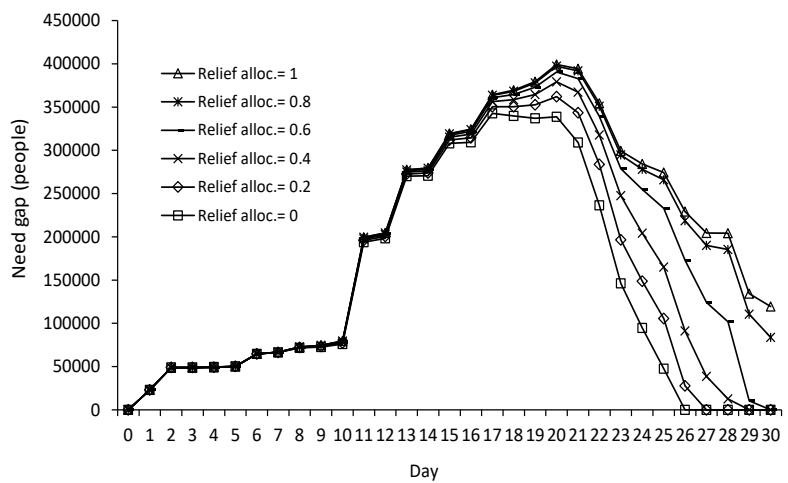

(d). Empirical Model - Need Gap

Fig. 4. Simulation Results for Empirical Model (Historical Pattern of Relief Demand) for Various Human Resource Allocation Policies (a-d)

Results indicate that allocating resource to relief operations without allocating the resources to capacity building causes slow and less people receiving assistance in the long run. As no resource is allocated to capacity building, there is no significant resource addition for relief operations. The increased organization capacity is only due to knowledge gained from the field. However, the organizational capacity increase is not significant so that, in the long run, the existing resources has less productivity due to continually high need gap. Consequently, it results in less people receiving help.

Because the effect of various allocation policy is not observable in the short-term, HOs tend to allocate more resources to relief operations due pressure of high surge of relief demand. However, based on the results, allocating resources to capacity building is necessary to sustain the effort of relief operations for the long-term. The results are supported by [8] who investigated that capacity building strategy is enduring strategy on $\mathrm{HO}$ performance, whereas relief strategy is a better-beforeworse $\mathrm{HO}$ performance.

Results demonstrate that investing all resources to capacity building appears to be the best policy to save more people and meet relief demand in the long run. Although building capacity is incapable to save people in early days, the organizational capacity positively supports relief operations after some days in a way that the organizational capacity provide resources and increases productivity. Consequently, it can save more people quickly in later days. By saving more people rapidly, knowledge gained due to experience in saving people gives positive impact to more capability of the HOs in relief operations.

Although fully allocation to capacity building appears to be best policy, in reality, HOs cannot allocate resources fully on the capacity building because there is minimum requirement for relief operation if HOs want to get finance from donors and stay in the field. There is a trade-off of allocation policy to distribute more on either relief operations or capacity building. For both base model and empirical model, results indicate that at least $20 \%$ of human resources need to be allocated for capacity building in order to sustain relief operations in the long run.

It is also worth to mention that the time required to fulfil relief demand is very much depending on the pattern of relief demand. It seems that constant relief demand requires less time to fulfil the demand than that of nonlinear relief demand.

\section{Conclusions}

The present study has developed a system dynamics simulation model for examining the allocation policy for relief operations and capacity building in humanitarian organizations. The conceptual model was built based on interviews with two HOs in Yogyakarta and parameterized with empirical data based on Mount Merapi disaster in 2010. Results indicate that, during disaster response, HOs need to allocate resource to capacity building, in addition to relief operations, in order to sustain the relief operations in the long run. It is suggested that at least $20 \%$ of the resources should be allocated to capacity building.

Although the model has been useful to demonstrate the allocation trade-off, some limitations still need to be highlighted. First, although the model is generic, the parameter values are only relevant for the typical disaster in the study (volcano eruption), different disaster and location of disaster may have different parameter values. Second, the conceptual model is elicited based on two HOs, more HOs are still needed to get representative model specification.

It is suggested that future research should thus focus on refining the conceptual model as well as testing the model to gain more confidence on the model. Last but not least, experiments could be conducted to explore the 
effect of productivity, knowledge gained from field, etc., which may be useful to increase efficiency in relief operations.

The authors gratefully acknowledge financial support from Higher Education Directorate (DIKTI), Indonesia, under research grant of Penelitian Unggulan Perguruan Tinggi (PUPT) - Universitas Gadjah Mada 2017. The authors also thank to Ryan Destryan for administering the interviews.

\section{References}

1. A. Thomas, and L. Kopczak, From logistics to supply chain management: the path forward in humanitarian sector. Fritz Institute (2005)

2. D. Kaatrud, R. Samii, and L. M. Van Wassenhove, UN Joint Logistics Center: a coordinated response to common humanitarian logistics concernes, Forced Migr. Rev. 18, 11-14 (2003)

3. L. Gustavsson, Humanitarian logistics: context and challenges, Forced Migr. Rev. 18, 6-8 (2003)

4. C. Ni, R. de Souza, Q. Lu, and M. Goh, M, Emergency preparedness of humanitarian organizations: A system dynamics approach, In M. Klumpp, S. de Leeuw, A. Regattieri, and R. de Souza, Humanitarian Logistics and Sustainability. Lecture Notes in Logistics, Springer International Publishing, 113-127 (2015)

5. D. A., McEntire, Issues in disaster relief: progress, perpetual problems and prospective solutions, Disaster Prev. Manag. 8, 351-366 (1999)
6. G. Heaslip, A. M. Sharif, and A. Althonayan, Employing a systems-based perspective to the identification of inter-relationships within humanitarian logistics, Int. J. Prod. Econ. 139, 377 392 (2012)

7. M. Besiou, O. Stapleton, and L. N. Van Wassenhove, L. N, Exploring the known and the unknown: Future possibilities of system dynamics for humanitarian operations, Working Paper 2010/74/TOM/ISIC, INSEAD Social Innovation Center, The Business School for the World (2010)

8. P. Goncalves, Balancing provision of relief and recovery with capacity building in humanitarian operations, Oper. Manag. Res. 4, 39-50 (2011)

9. J. D. Sterman. Business Dynamics: System Thinking and Modeling for a Complex World, McGraw-Hill Company, New York (2000)

10. P. M. Senge, The Fifth Disciplines. Doubleday; New York (1990)

11. B. Voight, E. Constantine, S. Siswowidjoyo, and R. Torley, Historical eruptions of Merapi Volcano, Central Java, Indonesia, 1768-1998, J. Volcanol. Geotherm. Res. 100, 69-138 (2000)

12. E. T. W. Mei, F. Lavigne, A. Picquout, E. de Belizal, D. Brunstein, D. Grancher, J. Sartohadi, N. Cholik, and C. Vidal, Lessons learned from the 2010 evacuations at Merapi volcano, J. Volcanol. Geotherm. Res. 261, 348-365 (2013) 